\title{
Formação de Professores e Práticas Pedagógicas no Contexto Escolar das Séries Iniciais
}

\author{
Daniela Haetinger ${ }^{1}$, Eliana Rela ${ }^{2}$, Lílian Schwab Gelatti. ${ }^{3}$, Mary Lúcia Pedroso Konrath ${ }^{4}$, \\ Tânia Kist $^{5}$, Marie Jane Soares Carvalho ${ }^{6}$, Rosane Aragon Nevado ${ }^{7}$ \\ danih@via-rs.net, erela@ucs.br, \\ liliangelatti@gmail.com,mary@cinted.ufrgs.br,taniak@unisc.br,marie@pesquisador.cnpq.br, \\ Rosane@edu.ufrgs.br
}

\begin{abstract}
This paper presents the very first analysis of a research project about pedagogical mediation and the use of digital and technological resources in scholar context of an elementary school. The study analyses the teacher's formation and their appropriation of digital culture; in the use of digital resources and media in classroom and the immersion of the teachers observed in situations where they can explore and evaluate a digital learning object.
\end{abstract}

Resumo. O presente artigo propõe a apresentação das primeiras análises da pesquisa realizada sobre o tema mediação pedagógica e uso de recursos informatizados no contexto escolar das Séries Iniciais. O recorte do estudo fundamenta-se na perspectiva da formação de professores e sua apropriação da cultura digital; na atual utilização de mídias e ferramentas digitais em sala de aula; na imersão dos sujeitos pesquisados em situação de exploração e avaliação de um objeto digital de aprendizagem.

\section{Novas Tecnologias e suas repercussões na Educação}

A virada do último milênio foi marcada pela popularização das novas tecnologias de informação e comunicação (NTIC) - computadores, internet, web e tantos outros recursos que suportam o trânsito de imensos e contínuos fluxos de informação, redes de pessoas, produtos e serviços, a criação e divulgação de produtos e manifestações culturais. Tudo isso acontecendo em espaços virtuais e flutuantes, desvinculados das antigas noções de tempo, espaço, status social e econômico.

Os sistemas e ferramentas informatizados são mais do que simples veículos de transmissão de informações porque transcendem os convencionais dispositivos e espaços de comunicação, e oferecem maior poder de interação entre os participantes dos processos comunicativos. Caracterizam-se como hipermídias, pois reúnem "várias mídias num suporte computacional [...]" [Laufer e Scavetta, 1997], potencialmente capazes de ampliar os sentidos e as habilidades envolvidas em sua utilização. As NTIC podem ainda ser definidas como: 
[...] Tecnologias intelectuais que amplificam, exteriorizam e modificam numerosas funções cognitivas humanas: memória (banco de dados, hiperdocumentos, arquivos digitais de todos os tipos), imaginação (simulações), percepção (sensores digitais, telepresença, realidades virtuais), raciocínios (inteligência artificial, modelização de fenômenos complexos). (LÉVY, 2000, p.157)

Autores como Alava (2002), Castells (2003), Pellanda (2000) e Tjara (2002) também destacam o potencial das hipermídias em relação à dinamização e ampliação das habilidades cognitivas, devido à riqueza de objetos e sujeitos com os quais nos permitem interagir; à possibilidade de extensão da memória e de atuação em rede; e pela democratização de espaços e ferramentas que facilitam o compartilhamento de saberes, a autoria, co-autoria, edição e a publicação de informações, mensagens, obras e produções culturais.

Nos últimos 10 anos, o uso das NTIC nos processos de ensino e aprendizagem tornou-se foco de debates e ações protagonizadas por governos, instituições de ensino, educadores e pesquisadores. As teorias e práticas associadas à informática na educação vêm repercutindo em nível mundial, justamente porque as ferramentas e mídias digitais oferecem à didática, objetos, espaços e instrumentos capazes de renovar as situações de interação, expressão, criação, comunicação, informação, cooperação e colaboração, tornando-as muito diferentes daquelas tradicionalmente fundamentadas na escrita e nos meios impressos.

Quanto às políticas públicas brasileiras, algumas iniciativas foram desencadeadas para promover a inclusão da população no contexto da Sociedade da Informação, como os programas TV Escola, Proinfo, Proformação, Paped e o Programa Sociedade da Informação, entre outros.

$\mathrm{O}$ acesso às redes de computadores por parte do sistema educativo vem sendo ampliado gradativamente, demonstrando que a potencialidade para fins didáticos deste meio, ainda tem muito a oferecer (GALLINI, 2004). Veja-se a crescente proliferação de laboratórios de informática em escolas brasileiras públicas e privadas, e da grande oferta de cursos via internet (até mesmo em nível de graduação em licenciaturas e pedagogia).

Porém, as hipermídias são incompatíveis com modelos educacionais baseados no poder do educador, na comunicação unilateral, na repetição, no controle do aprendiz. Isto porque elas extrapolam os limites temporais e espaciais da sala de aula, oportunizam atos comunicativos multimensionais e descentralizados, atividades cooperativas e colaborativas, acesso a todo tipo de informações e sujeitos. Essa riqueza simbólica, relacionada à pluralidade de objetos, linguagens e mídias, auxilia o educando a desenvolver suas meta-habilidades, a se comunicar e se movimentar em um mundo mediado pela tecnologia, a se adaptar a diferentes situações.

A concepção de aprendizagem exaustivamente disseminada nos dias de hoje ressalta o quão importante são as interações entre sujeitos e objetos para a aprendizagem. Seguindo tal perspectiva, (SILVA, 2001) destaca a pedagogia interativa, uma proposta de valorização do papel do professor como mediador de novas e recorrentes interações e encorajador da rede de conhecimentos que os alunos constroem e do desenvolvimento de novas competências comunicativas.

Apesar dos discursos inquietantes e iniciativas mobilizadoras, assistimos a uma situação extremamente paradoxal: enquanto as crianças interagem com mais informações audiovisuais e meios eletrônicos do que com mídias impressas, vivendo em um mundo permeado pelas novas tecnologias, seus professores foram formados para 
ministrar um ensino baseado em técnicas pedagógicas, conteúdos e materiais convencionais. Muitos educadores acabam apenas reproduzindo os modelos tradicionais de ensino quando propõem atividades com objetos digitais em sala de aula, desconsiderando a transição do paradigma aprendizagem/sala de aula/escola para aprendizagem/redes sociais/sociedade do conhecimento.

Também é comum a confusão entre inovação educacional com a simples introdução de tecnologias informatizadas nos ambientes de ensino sem a adoção de didáticas compatíveis. Mesmo com diretrizes gerais voltadas à atualização profissional de professores e à renovação do setor educacional, as transformações que as políticas públicas brasileiras podem desencadear no contexto escolar e na práxis pedagógica estão longe de apontar para uma verdadeira incorporação das atuais perspectivas educativas. O preparo dos docentes brasileiros para a utilização de mídias e objetos digitais como materiais didático-pedagógicos ainda deixa muito a desejar.

Considerando a problemática e o cenário apresentado, o presente artigo tem como principal objetivo ampliar e contribuir com o debate e a produção científica relacionada à repercussão das NTIC no contexto escolar por meio da análise da formação de professores de Séries Iniciais do Ensino Fundamental e das propostas destes profissionais para o uso das novas tecnologias em sala de aula.

\section{Contexto da pesquisa}

A pesquisa foi planejada e desenvolvida em 2006, por uma equipe interdisciplinar de educadoras-pesquisadoras, durante o curso da disciplina "Avaliação e Produção de Materiais para a Inovação Didático-pedagógica em Educação a Distância" dos Programas de Pós-Graduação em Educação e em Informática na Educação, da Universidade Federal do Rio Grande do Sul.

A carência de estudos que contemplassem a realidade local mobilizou o grupo a levantar e analisar dados sobre a utilização de ferramentas digitais junto aos alunos das Séries Iniciais, a formação e o preparo de seus professores para o uso de meios e recursos informatizados em situações de ensino-aprendizagem, e o modo como estes docentes exploram e avaliam o objeto de aprendizagem "Nós no Mundo". Adotou-se esse software como referencial para a pesquisa, principalmente pelos seguintes motivos:

- trata-se de um sistema digital flexível e adaptável a diferentes contextos, permitindo a adequação e inserção de dados, conforme o planejamento didáticopedagógico de cada professor e os interesses e necessidades dos alunos;

- foi especialmente modelado para estudantes das Séries Iniciais, a partir de perspectivas interacionistas e construtivistas;

- $\quad$ possibilita navegação e exploração livres, sem impor ordem pré-definida às interações;

- $\quad$ propõe atividades abertas, que não fornecem feedback baseado em acerto e erro;

\footnotetext{
1 Objeto de aprendizagem refere-se a um recurso, material ou ferramenta digital, interativo, flexível, durável, reaproveitável, alterável e adaptável a diferentes contextos e circunstâncias, que possa ser utilizado para potencializar situações de ensino (presencial e a distância) e aprendizagens.
} 
- $\quad$ encontra-se em total consonância com os Parâmetros Curriculares Nacionais.

Do ponto de vista pedagógico, o objeto "Nós no Mundo" enfatiza o tema pluralidade cultural, reunindo um conjunto inicial de atividades que perpassam conteúdos associados à expressão e comunicação, língua portuguesa, matemática, história e geografia. As interfaces utilizam a linguagem textual (em maior escala) e iconográfica (em menor escala), para convidar os usuários a interagir, contribuindo com o processo de alfabetização e o aprimoramento das competências de leitura e escrita, entre outras.

Para utilizá-lo, o professor solicita o seu cadastro no sistema². Após autorização dos administradores, poderá cadastrar seus alunos do modo que quiser. Somente estudantes cadastrados em uma mesma turma conseguem visualizar e interagir com as produções de seus colegas. Tanto o perfil de professor quanto o de aluno permitem a inserção e a edição de novos dados, mas cada um altera apenas a sua própria produção. Todos esses mecanismos oportunizam a livre expressão, organização e formação de um espaço customizado, com a identidade de determinado grupo de alunos sob orientação e acompanhamento do seu professor regular.

Ao ingressarem no sistema, os alunos podem ler uma pequena história que provoca a imaginação infantil, incentiva a pesquisa, o autoconhecimento e a compreensão de identidades pessoais e coletivas, instigando os aprendizes a descobrirem quem eles são eles no mundo. Também é possível escolher e realizar cinco diferentes atividades: Identificação, Diário, Entrevistas, Alimentação e Navegando na Internet, sendo que nesta última os alunos visitam e interagem com sites e espaços virtuais inseridos no sistema pelo seu próprio professor, conforme o momento programático e as expectativas e maturidade da turma. Todas as atividades são apresentadas sob a forma de convites ao aprendiz. A navegação é totalmente livre, sem uma ordem pré-definida ou linear.

\section{Resultados obtidos}

O grupo de sujeitos analisados foram 18 professoras de Séries Iniciais do Ensino Fundamental, que atuam regularmente em uma escola privada de Educação Infantil, Ensino Fundamental e Médio da zona sul da cidade de Porto Alegre, com cerca de 2.000 alunos. As docentes pesquisadas ministram 20,2h/aula semanais, em média, e costumam atender apenas uma turma. A média de alunos por turma é de 24,9 alunos.

Foram coletados e analisados dados sobre a formação inicial e continuada dos sujeitos pesquisados, o preparo destes para o uso de objetos de aprendizagem junto aos seus alunos, o contexto geral no qual esses profissionais atuam, o tipo de recursos informatizados que eles propõem às suas turmas, e a exploração e avaliação do objeto de aprendizagem "Nós no Mundo" por parte desses professores. Durante a pesquisa de campo, o grupo de pesquisa ministrou uma Oficina de Formação $^{3}$, realizada no laboratório de informática da escola onde atuam os sujeitos da pesquisa. Nesta ocasião foram aplicados quatro instrumentos de coleta de dados.

\footnotetext{
2 "Nós no Mundo" é acesado via internet e web, possui banco de dados associado a servidor e encontra-se disponível em: http://pead.faced.ufrgs.br/objetos/nosnomundo2/

${ }^{3} \mathrm{O}$ grupo de pesquisa desenvolveu um site de apoio à oficina e à aprendizagem das professoras pesquisadas, disponível em http://www.espie.cinted.ufrgs.br/ mary/oficinaformacao/ 
A pesquisa valeu-se de abordagens de caráter qualitativo e quantitativo, sendo esta última principalmente adotada no procedimento de tabulação e análise de dados. É importante considerar que "a análise qualitativa não rejeita toda e qualquer forma de quantificação” [BARDIN, 1977, p. 115].

Entre as 18 professoras pesquisadas, quatro atendem turmas de $1^{\mathrm{a}} \mathrm{s}$ séries; cinco de $2^{\mathrm{a}} \mathrm{s}$ séries; cinco de $3^{\mathrm{a}} \mathrm{s}$ séries e quatro de $4^{\mathrm{a}} \mathrm{s}$ séries do Ensino Fundamental. A Tabela 1 apresenta o panorama geral sobre a formação dessas professoras, englobando o nível de ensino cursado e o tipo de instituição em que cada curso foi realizado - pública ou privada. Os percentuais relativos ao tipo de instituição referem-se ao universo específico de cada nível de ensino, não ao número total de pesquisadas.

Tabela 1 - Formação profissional do universo pesquisado

\begin{tabular}{|l|c|c|c|c|}
\hline \multicolumn{1}{|c|}{ Nível de ensino } & $\begin{array}{c}\text { Número de } \\
\text { professoras }\end{array}$ & $\begin{array}{c}\text { Em } \\
\text { instituição } \\
\text { pública }\end{array}$ & $\begin{array}{c}\text { Em } \\
\text { instituição } \\
\text { privada }\end{array}$ & $\begin{array}{c}\text { Não informa } \\
\text { instituição }\end{array}$ \\
\hline Magistério/Normal & 7 & 2 & 5 & 0 \\
\hline Graduação em Pedagogia & 14 & 6 & 7 & 1 \\
\hline Outras Graduações & 3 & 0 & 18 & 0 \\
\hline Especialização & 11 & 1 & 10 & 0 \\
\hline Mestrado & 2 & 18 & 0 & 0 \\
\hline
\end{tabular}

A formação em escolas privadas é majoritária em quase todos os níveis de ensino - Ensino Médio (Magistério e Normal), graduações e especializações. Somente em nível de mestrado a formação em escola pública é predominante. Considerando-se o número total de cursos realizados em todos os níveis, apenas $29,5 \%$ deles foram feitos em instituições públicas frente a 70,5\% em instituições privadas. Isto pode evidenciar a importância do ensino privado na formação dos docentes das Séries Iniciais, indicando um déficit na oferta do ensino público.

Todas as professoras com Magistério ou Normal cursaram posteriormente algum tipo de graduação e sete pesquisadas são especialistas em alguma área do conhecimento. Isso pode demonstrar a preocupação dos docentes com a formação continuada e reflete a atual necessidade que os profissionais têm de se manterem em constante aperfeiçoamento, visto que a educação e tantos outros segmentos sociais encontram-se hoje em plena transformação. Já a qualificação em nível de mestrado ainda é pouco vigente entre os professores das Séries Iniciais e, em nível de doutorado, é absolutamente inexistente.

Quanto ao período de formação informado, os cursos de Magistério/Normal foram todos concluídos há 10 anos ou mais (indicando a defasagem deste tipo de formação). A maior parte das graduações em pedagogia (80\%) foi concluída entre 2000 e 2006, assim como 66,7\% de outras graduações. As especializações são recentes (63,6\% concluídas entre 2000 e 2006), enquanto que todos os mestrados foram finalizados em 2006.

A formação em nível de graduação e pós-graduação é bastante recente, evidenciando a transformação do perfil dos professores de Séries iniciais. Se há duas décadas atrás, um curso de Normal ou Magistério poderia ser condição suficiente para alguém atuar como professor das Séries Iniciais, hoje o mercado de trabalho exige a graduação (todos os pesquisados são graduados) e valoriza a pós-graduação. 
Outro aspecto a ser destacado é o tipo de graduação e especialização que o universo pesquisado cursou. Sobre o universo total, 12 professoras são graduadas em Pedagogia/Séries Iniciais, duas em Pedagogia Orientação/Supervisão; uma em Pedagogia/Educação Infantil; uma em Psicologia; uma em Nutrição e uma em Biblioteconomia.

Sobre as especializações cursadas, quatro são em alfabetização; quatro em psicopedagogia; uma em educação; uma em psicologia e uma em gestão educacional. Apenas duas pesquisadas são mestres, sendo uma delas em Educação e outra em Educação Especial. Ambas cursaram mestrados em instituição pública, o que evoca o papel de destaque que a universidade pública adquire hoje em relação a esse nível de ensino e, consequentemente, à produção científico-acadêmica, ao estudo e à descoberta de novas teorias e possibilidades no âmbito educacional.

As pesquisadas não indicaram a realização de qualquer capacitação, curso de extensão, especialização ou outro tipo de programa que pudesse contribuir positivamente com o uso da informática na educação, confirmando a problemática apresentada na introdução do presente artigo. Referência ao conhecimento de informática foi apenas apontada por uma única graduação incompleta em análise de sistemas. Assim, o uso de recursos informatizados com os alunos das Séries Iniciais parece dar-se estritamente pela práxis educativa e difusão das novas mídias, mas não devido à formação dos professores ou capacitações realizadas para este fim.

A Tabela 2 apresenta a relação entre os recursos informatizados utilizados e o número de pesquisados (sobre o universo total) que adotam cada um deles em sua práxis pedagógica.

Tabela 2 - Recursos informatizados utilizados nas Séries Iniciais

\begin{tabular}{|l|c|l|c|}
\hline $\begin{array}{c}\text { Ferramentas e recursos } \\
\text { digitais utilizados }\end{array}$ & $\begin{array}{c}\text { Número de } \\
\text { professoras } \\
\text { que utilizam }\end{array}$ & \multicolumn{1}{|c|}{$\begin{array}{c}\text { Ferramentas e recursos } \\
\text { digitais utilizados }\end{array}$} & $\begin{array}{c}\text { Número de } \\
\text { professoras } \\
\text { que utilizam }\end{array}$ \\
\hline Jogos educativos & 18 & História infantil digital & 10 \\
\hline Pesquisa na internet & 17 & CDs temáticos & 6 \\
\hline Editor texto & 15 & Logos & 4 \\
\hline Jogos de entretenimento & 14 & Simulações/animações & 4 \\
\hline Internet & 14 & Arquivos de som/música & 3 \\
\hline Arquivos vídeo/foto & 13 & CDs/consulta de conteúdos & 3 \\
\hline Editor gráfico & 12 & RPGs & 3 \\
\hline Scanner & 12 & Editor HTML & 2 \\
\hline Editor de apresentações & 11 & E-mail & 2 \\
\hline
\end{tabular}

Todas as professoras utilizam jogos educativos com seus alunos, e 14 usam jogos de entretenimento, confirmando a importância do aspecto lúdico na formação das crianças. A pesquisa temática na internet é o segundo recurso usado pelo maior número de professoras (17), revelando que as docentes estão preocupadas em estimular a curiosidade e o gosto pela pesquisa desde a infância. Também é alto o índice de utilização de editores de texto e arquivos de vídeo e foto. São muitas as professoras que adotam arquivos de vídeo e foto em suas aulas, mas nenhuma utiliza câmera de vídeo digital, o que ampliaria as possibilidades de autoria e criação dos alunos.

Apesar das histórias infantis acompanharem o desenvolvimento de qualquer criança e da ampla oferta deste tipo de material em formato digital, apenas 10 professoras trabalham com histórias infantis via computador em suas classes. Recursos 
de grande potencial didático-pedagógico, como os logos, as animações e a simulações são adotados por somente quatro professoras.

O e-mail ainda é pouco utilizado na mediação pedagógica das Séries Iniciais. É ainda menor o número de professoras que propõem atividades com comunicadores instantâneos ou a participação em comunidades virtuais. Também não há indicação de uso de blogs ou fotologs. Esses fatores ressaltam que as inúmeras possibilidades de interconexão entre pessoas e da formação de redes na sociedade do conhecimento têm sido pouco exploradas, representando um forte sinal de que o compartilhamento de informações, experiências e saberes ainda estão confinados nos limites da sala de aula e do espaço físico escolar.

Com as novas tecnologias, os professores poderiam, por exemplo, propor a comunicação eletrônica entre crianças de diferentes turmas, escolas ou até mesmo regiões e países, algo que certamente enriqueceria o conhecimento dos pequenos aprendizes, a abordagem didática e a formação dos alunos para lidar com a diversidade cultural, entre outros aspectos.

Tabela 3 - Número de professoras que utilizam recursos informatizados em cada uma das Séries Iniciais

\begin{tabular}{|l|c|c|c|c|}
\hline $\begin{array}{l}\text { Ferramentas e recursos } \\
\text { informatizados utilizados }\end{array}$ & $\mathbf{4}^{\text {as }}$ séries & $\mathbf{3}^{\text {as }}$ séries & $\mathbf{2}^{\text {as }}$ séries & $\mathbf{1}^{\text {as }}$ séries \\
\hline Jogos educativos & 4 & 5 & 5 & 4 \\
\hline Pesquisa temática Internet & 4 & 5 & 5 & 3 \\
\hline Editor texto & 5 & 5 & 5 & 1 \\
\hline Jogos de entretenimento & 4 & 4 & 4 & 2 \\
\hline Internet & 4 & 5 & 5 & 0 \\
\hline Arquivos de vídeo/foto & 3 & 4 & 4 & 2 \\
\hline Editor gráfico & 0 & 4 & 5 & 3 \\
\hline Scanner & 1 & 4 & 5 & 1 \\
\hline Editor de apresentações & 4 & 5 & 2 & 0 \\
\hline Câmera fotográfica digital & 0 & 5 & 5 & 1 \\
\hline História infantil digital & 1 & 3 & 5 & 1 \\
\hline CDs temáticos & 1 & 3 & 2 & 0 \\
\hline Logos & 0 & 0 & 0 & 4 \\
\hline Simulações/animações & 1 & 2 & 0 & 1 \\
\hline Arquivos de som/música & 1 & 2 & 0 & 0 \\
\hline CDs para consulta & 2 & 1 & 0 & 0 \\
\hline RPGs & 1 & 2 & 0 & 0 \\
\hline Editor HTML & 2 & 0 & 0 & 0 \\
\hline E-mail & 1 & 1 & 0 & 0 \\
\hline Comunicador instantâneo & 0 & 1 & 0 & 0 \\
\hline Comunidades virtuais & $\mathbf{5}$ & 5 & $\mathbf{5}$ & \\
\hline Total de professoras por série & & & & \\
\hline
\end{tabular}

A Tabela 3 apresenta um recorte mais específico, indicando o número de docentes que adota recursos informatizados com alunos de cada uma das Séries Iniciais. Observa-se que as professores de 3as séries são as que recorrem a maior variedade de recursos, seguidos pelas de 4 as e 2 as séries, enquanto que as de 1as série são os que adotam a menor diversidade de recursos em suas salas de aula. 
Além desses dados, a Tabela 3 também suscita questionamentos importantes como:

- Por que os resultados apresentam as professoras de 4as séries utilizando jogos digitais, enquanto um índice menor recorre a estes recursos nas demais séries?

- Por que a linguagem logo é só usada pelas docentes de 1as séries?

- Por que apenas professoras de 4as séries não propõem o uso de editor gráfico e câmera fotográfica digital?

- Por que as animações e simulações, como recursos de grande apelo visual e cognitivo, não são adotadas junto às 2as séries?

- Por que as histórias infantis digitais têm sido usadas por um maior número de professoras de 2 as e 3 as séries, e pouco aproveitadas pelas de 1as séries?

- Por que os arquivos de som e música são totalmente desconsiderados para as 1as e 2as séries?

- Por que somente as docentes de 3as séries fomentam o uso de comunicadores instantâneos em suas classes?

- Por que a participação em comunidades virtuais são propostas apenas pelas professoras de 2as séries?

Respostas precisas para essas questões exigem a continuidade e a complementação da pesquisa realizada. Mas as ocorrências levantadas até o momento sugerem a falta de preparo e de uma visão pedagógica mais ampla sobre o uso de recursos informatizados nas salas de aula das Séries Iniciais.

Quando questionadas sobre os motivos que impediam ou dificultavam a utilização de recursos informatizados como objetos didático-pedagógicos, somente quatro pesquisadas se manifestaram. Entre estas, duas indicaram falta de capacitação específica, enquanto duas afirmaram que desconhecem recursos que possam ser usados com seus alunos e também sentem falta de capacitação específica.

Quanto à exploração do objeto de aprendizagem "Nós no Mundo", as professoras pesquisadas foram convidadas a explorá-lo livremente, enquanto eram observadas pelas pesquisadoras. Após a livre exploração, as professoras dedicaram-se à avaliação do "Nós no Mundo" como um recurso didático-pedagógico para as Séries Iniciais. A partir de critérios de avaliação pré-definidos, foram obtidos os seguintes resultados entre os pesquisados:

- 17 professoras afirmam que o objeto é compatível com o nível cognitivo dos alunos;

- 16 professoras avaliaram o objeto como compatível com os objetivos das Séries Iniciais;

- 15 professoras vislumbram o uso pedagógico do objeto para diferentes conteúdos;

- 14 professoras consideram o objeto compatível com as expectativas dos alunos; 
- 11 professoras afirmam que o objeto permite a criação de novas possibilidades de uso;

- 16 professoras destacam que o objeto instiga a curiosidade e o interesse pela pesquisa.

As pesquisadas também indicaram o seu grau de satisfação em relação a outras qualidades do objeto, através da eleição de cada quesito como "Não satisfatório" (NS), "Pouco satisfatório" (PS), "Satisfatório" (S), "Muito satisfatório" (MS), "Plenamente satisfatório" (PLS) ou "Não foi possível observar" (NFP), conforme dados apresentados na Tabela 5.

Tabela 5 - Grau de satisfação em relação às qualidades do "Nós no Mundo"

\begin{tabular}{|l|c|c|c|c|c|c|}
\hline Qualidades do objeto & NS & PS & S & MS & PLS & NFP \\
\hline Navegação não-linear & 2 & 5 & 8 & 2 & 1 & 0 \\
\hline $\begin{array}{l}\text { Quantidade de informações distribuídas } \\
\text { em cada tela }\end{array}$ & 0 & 2 & 15 & 1 & 0 & 0 \\
\hline Visual das telas & 0 & 8 & 7 & 1 & 2 & 0 \\
\hline $\begin{array}{l}\text { Abordagem de diversas áreas do } \\
\text { lonhecimento }\end{array}$ & 0 & 7 & 9 & 1 & 0 & 1 \\
\hline Relação entre teoria e prática & 1 & 4 & 9 & 2 & 1 & 1 \\
\hline $\begin{array}{l}\text { Possibilidade de utilização em todas as } \\
\text { Séries Iniciais }\end{array}$ & 2 & 2 & 9 & 4 & 1 & 0 \\
\hline $\begin{array}{l}\text { Mensagens fornecidas para confirmar as } \\
\text { ações que o usuário executa }\end{array}$ & 0 & 0 & 12 & 2 & 4 & 0 \\
\hline $\begin{array}{l}\text { Modo como o usuário pode inserir, } \\
\text { editar e excluir informações }\end{array}$ & 0 & 3 & 8 & 4 & 3 & 0 \\
\hline \begin{tabular}{l} 
Total de professoras \\
\hline
\end{tabular} & & $\mathbf{1 8}$ & & \\
\hline
\end{tabular}

De modo geral, os resultados da avaliação foram satisfatórios em relação às qualidades gerais e usabilidade do objeto, e também quanto à aplicabilidade pedagógica e à compatibilidade de seus conteúdos e atividades com a realidade das Séries Iniciais. O quesito de avaliação com maior índice de respostas "pouco satisfatório" refere-se ao visual das telas. Aliás, foi nesse sentido que as pesquisadas indicaram o maior número de sugestões de melhorias para o objeto, sendo estas relacionadas à implementação de "mais cores", "mais animações", "mais desenhos", confirmando o peso e a importância dada pelas docentes ao apelo visual, em detrimento das possibilidades pedagógicas de cada atividade do objeto.

\section{Conclusão}

Esta investigação reforçou a hipótese do grupo em relação à necessidade de investimento na formação continuada de professores das Séries Iniciais na área de Informática na Educação, envolvendo o conhecimento dos aspectos técnicos e pedagógicos que perpassam o uso dessas ferramentas.

Partindo desta necessidade o grupo pretende, a partir dos dados coletados e das necessidades observadas, realizar cursos de extensão e aperfeiçoamento, buscando oferecer subsídios aos professores interessados pelo tema Informática na Educação, no qual possa se fazer um acompanhamento presencial e a distância, compartilhando conhecimentos e olhares diferenciados sobre as novas tecnologias de informação e comunicação e seu uso pedagógico. 


\section{Referências}

Alava, Séraphin et alli. Ciberespaço e formações abertas: rumo a novas práticas educacionais. Porto Alegre: Artmed, 2002.

Antunes, Celso. Novas maneiras de ensinar, novas formas de aprender. Porto Alegre: Artmed, 2002.

Bardin, L. Análise de conteúdo. Lisboa: Edições 70, 1977.

Castells, Manuel. A Galáxia da Internet: reflexões sobre a internet, os negócios e a sociedade. Rio de Janeiro: Jorge Zahar Editor, 2003.

Gallini, Luciano. La scuola in rete. Roma: Editori Laterza, 2004.

Lévy, Pierre. Cibercultura. $2^{a}$ ed. São Paulo: Editora 34, 2000.

Konrath, Mary L. P., et alli. "Nós no Mundo": Objeto de Aprendizagem voltado para o $1^{\circ}$ Ciclo do Ensino Fundamental. RENOTE - Revista Novas Tecnologias na Educação. Porto Alegre: CINTED/UFRGS, v.4, n.1, julho de 2006.

Moran, José Manuel; MASETTO, Marcos T.; BEHRENS, Marilda Aparecida. Novas Tecnologias e mediação pedagógica.Campinas: Papirus, 2004.

Pellanda, Nise M.C; CAMPOS, Eduardo. (Org.). Ciberespaço: um hipertexto com Pierre Lévy. Porto Alegre: Artes e Ofícios, 2000.

Rela, Eliana. Aportes Teórico-metodológicos para a compreensão da aprendizagem mediada pela tecnologia em cursos de formação de professores. In: Simpósio Brasileiro de Informática na Educação - SBIE, 2005, Juiz de Fora. XVI Simpósio Brasileiro de Informática na Educação. Juiz de Fora: Fernanda Cláudia Alves Campos, 2005.

Ribeiro, Célia. Metacognição: um apoio ao processo de aprendizagem. Psicologia, reflexão e crítica. Porto Alegre: Scielo, 2003, vol. 16, no. 1 Disponível em: $<$ http://www.scielo.br/scielo.php?script=sci_arttext\&pid=S0102-

$79722003000100011 \& \operatorname{lng}=$ pt\&nrm=iso $>$. Acesso em julho de 2006.

Scavetta, S. \& Lauffer, R. Texte, Hipertexte, Hipermedia. Paris, Intro, 1997.

Silva, Marco. Sala de aula interativa. Rio de Janeiro: Quartet, 2001.

Tjara, Sanmya F. Comunidades Virtuais: um fenômeno na sociedade do conhecimento. São Paulo: Érica, 2002. 